\title{
Testing models of the Tertiary paleomagnetic field
}

\author{
David A. Schneider ${ }^{a}$ and Dennis V. Kent ${ }^{b}$ \\ ${ }^{a}$ Centre des Faibles Radioactivités, Laboratoire Mixte CNRS-CEA 91198, Gif-sur-Yvette, France \\ ${ }^{b}$ Lamont-Doherty Geological Observatory and Department of Geological Sciences, Columbia University, Palisades, N.Y. 10964, USA
}

Received February 8, 1990; revised version accepted June 28, 1990

\begin{abstract}
We examine selected paleomagnetic data of Tertiary age in order to assess previously suggested models of the non-dipole portion of the paleomagnetic field. Data from three localities on the African plate (from DSDP Leg 73, ODP Leg 115 and from Gubbio) indicate that the axial octupole contribution was near zero in the Paleocene and was likely no greater than $5-6 \%$ of the axial dipole in the Oligocene. Additional data from North America, which can be linked to Africa using well-known relative plate motion parameters, suggest that a positive axial quadrupole field has been present throughout the Tertiary. To investigate some of the practical consequences of these estimates, we apply a non-dipole field model ( 3 to $4 \%$ $\left.g_{2}^{0} / g_{1}^{0}, 0 \% g_{3}^{0} / g_{1}^{0}\right)$ to paleomagnetic data from two ODP sites on the African plate (Sites 710, 711) and from the Deccan Traps. We show that paleomagnetic directions from these deep-sea sediments and from this flood basalt province appear consistent with a fixed hotspot model, suggesting in particular that there has been little or no Cenozoic drift of the Réunion hotspot.
\end{abstract}

\section{The paleomagnetic field configuration}

The application of paleomagnetic measurements to tectonic studies requires that the paleomagnetic reference field be accurately known. Usual practice in most tectonic studies invokes the dipole hypothesis to determine paleolatitude from the observed paleomagnetic directions. Observations from rocks that are only a few million years old generally support the dipole hypothesis: the time-averaged field configuration largely matches the field of a geocentric axial dipole (GAD); however, non-dipole components can also be detected in the time-averaged field $[1,2,3,4]$. This long-term non-dipole field amounts to a few percent of the geocentric axial dipole and suggests that in detailed tectonic studies, non-dipole field effects cannot be neglected without consequence.

Although these non-dipole components of the mean field have been relatively small during the past few million years (less than 5\% of the GAD), larger non-dipole fields may have existed during other intervals in earth history. Indeed, two spherical harmonic studies of the time-averaged field available for pre-Pliocene times [2,5] indicate significantly larger non-dipole fields during parts of the Tertiary and Mesozoic, amounting at times to $10-15 \%$ or more of the GAD. Non-dipole components of such magnitudes would lead to substantial systematic errors in paleomagnetic pole positions and thus could complicate tectonic interpretations and reconstructions considerably. In this paper we attempt to test the reality of these prior indications of large non-dipole contributions.

Prior models of pre-Pliocene non-dipole fields $[2,5]$ have been determined using global paleomagnetic data compilations. Because the Plio-Pleistocene age paleomagnetic field has, in general, been found to be axially symmetric $[3,4]$, it appears reasonable to assume that the Tertiary age paleomagnetic field can be adequately described by including only the two lowest-degree zonal Gauss coefficients: $g_{2}^{0}$ (the axial quadrupole) and $g_{3}^{0}$ (the axial octupole). To estimate one or both of these non-dipole components, prior analyses explicitly compensated for known plate motions (using parameters determined from marine magnetic anomalies and fracture zone trends) and derived estimates of spherical harmonic terms from the resultant global data sets. In this analysis, some of the results of the prior global studies are tested using data from the African plate alone, by comparing the variation in paleomagnetic field 
directions over Africa with the predictions of a given non-dipole field model. In particular, we test previously suggested values for the zonal octupole field using relatively new data that were not included in the previous non-dipole field studies. A further advantage of restricting the analysis to a single plate is that we eliminate the possible influence of systematic errors stemming from the plate reconstruction.

Although it is more difficult, we would also like to test previously suggested values for the zonal quadrupole. The quadrupole component, being a lower-degree term than the octupole, will not give rise to a detectable anomalous variation in paleomagnetic direction over the single plate studied. We can only evaluate quadrupole field models using data from more widely separated longitudes and have attempted to do this using selected data from western North America. Because the relative motion of North America with respect to Africa is well-known, introducing data from North America should, in principle, introduce little error. The possibility of internal deformation within North America itself, however, is more difficult to address. We discuss this problem below in our consideration of the quadrupole results. Two intervals were selected for study: $60-65$ Ma (corresponding, nominally, to the Paleocene) and $30-40 \mathrm{Ma}$ (nominally the Oligocene). For each interval, we consider a small set of data (Table 1) from three regions on the African plate (Fig. 1): the western Indian Ocean basin; the area of the Walvis ridge and Angola abyssal plain; and the northern promontory of the African plate in the Mediterranean. We anticipated that such a wide distribution of data sites would make a

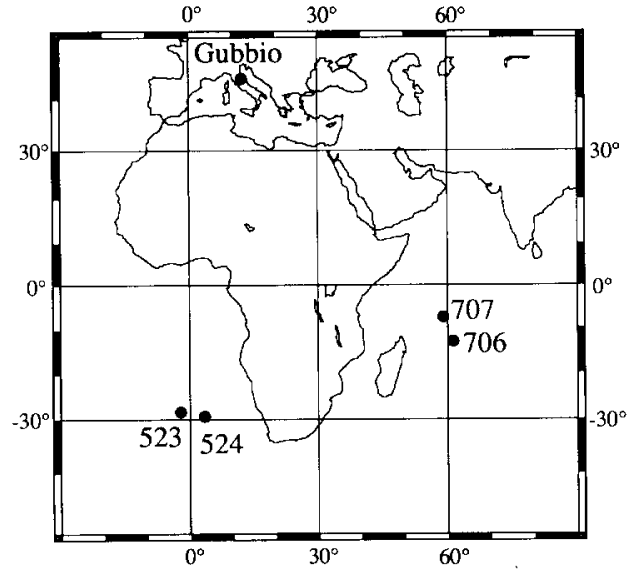

Fig. 1. Sites on the African plate used to test models of the paleomagnetic field. DSDP and ODP site numbers identify ocean drilling sites.

single-plate test of the field configuration most sensitive. Moreover, by using sites that are reasonably well-balanced between northern and southern hemispheres, the octupole might be estimated independently of the possible quadrupole contribution. These requirements essentially mandated the use of inclination-only paleomagnetic data: from azimuthally unoriented deep-sea cores, or from formations which may have been tectonically rotated.

\section{Method}

To test whether the data are compatible with a particular non-dipole field model we use an algorithm developed originally to calculate poles using paleomagnetic data from oceanic plates [6]. In this application, the colatitude $(\theta)$ associated

TABLE 1

Data localities

\begin{tabular}{|c|c|c|c|c|}
\hline$\overline{\text { Region }}$ & Site & $\begin{array}{l}\text { Lat. }\left(^{\circ}\right) \\
(\mathrm{N})\end{array}$ & $\begin{array}{l}\text { Long. }\left({ }^{\circ}\right) \\
(\mathrm{E})\end{array}$ & Ref. \\
\hline \multirow{2}{*}{$\begin{array}{l}\text { Angola Abyssal Plain/ } \\
\text { Walvis Ridge }\end{array}$} & DSDP Site 523 & -28.55 & -2.25 & [18] \\
\hline & DSDP Site 524 & -29.48 & 3.51 & [18] \\
\hline \multirow[t]{2}{*}{ Mascarene Plateau } & ODP Site 706 & -13.12 & 61.37 & [11] \\
\hline & ODP Site 707 & -7.55 & 59.02 & {$[14]$} \\
\hline \multirow[t]{2}{*}{ Italy } & Gubbio/Contessa & 43.38 & 12.57 & {$[8]$} \\
\hline & Gubbio & 43.37 & 12.57 & [9] \\
\hline \multirow[t]{2}{*}{ North America } & Mogollon-Datil Field & 33 & -107 & {$[21]$} \\
\hline & Nacimiento Fm. & 36.55 & -107.92 & [23] \\
\hline
\end{tabular}


with each observation of paleomagnetic inclination $(I)$ is calculated using [3]:

$$
\begin{aligned}
\tan (I)= & {\left[2 \cos \theta+G 2\left((9 / 2) \cos ^{2} \theta-(3 / 2)\right)\right.} \\
& \left.+G 3\left(10 \cos ^{3} \theta-6 \cos \theta\right)\right] / \\
& {[\sin \theta+G 2(3 \sin \theta \cos \theta)} \\
& +G 3\left((15 / 2) \sin \theta \cos ^{2} \theta\right. \\
& -(3 / 2) \sin \theta)]^{-1}
\end{aligned}
$$

where upper case denotes ratios of the zonal Gauss coefficients to the GAD; i.e., $G 2=g_{2}^{0} / g_{1}^{0}$ and $G 3=g_{3}^{0} / g_{1}^{0}$. The acceptability of a particular non-dipole field model is evaluated using the $\chi^{2}$ statistic determined from the pole-fitting algorithm by comparing the observed and calculated colatitudes. If the $\chi^{2}$ value calculated for a particular field model is too large, we reject the null hypothesis that the model fits the data. Acceptable models are then those which render $\chi^{2}$ less than a critical value and the best-fitting non-dipole field model is taken to be the one that minimizes the computed $\chi^{2}$ value.

\section{Axial octupole}

\subsection{Paleomagnetic data}

We consider data from ocean drilling sites in the area of the Walvis Ridge (DSDP Leg 73) and the Mascarene Plateau (ODP Leg 115), and from land-based data from Gubbio in the Apennines of peninsular Italy (Tables 2 and 3). As mentioned, we presume that this part of Italy was on the Adriatic promontory of the African plate following the arguments of Channell et al. [7] and examine this assumption more fully below. Because the cores from the ocean drilling legs are not azimuthally oriented, and because of the possibility of vertical axis rotation of the Italian sections,

TABLE 2

Paleocene inclination data

\begin{tabular}{llrll}
\hline Site & $\begin{array}{l}\text { Age } \\
(\mathrm{Ma})\end{array}$ & $\begin{array}{l}\text { Incl. } \\
\left({ }^{\circ}\right)\end{array}$ & $\begin{array}{l}\text { Std error } \\
\text { in incl. } \\
\left({ }^{\circ}\right)\end{array}$ & $\begin{array}{l}\text { Std error in } \\
\text { paleo-colat. } \\
\left({ }^{\circ}\right)\end{array}$ \\
\hline DSDP Site 524 & $60-65$ & -64.2 & 1.0 & 1.3 \\
ODP Site 707 & $63-65$ & -43.3 & 2.0 & 1.5 \\
Gubbio & $60-66$ & 42.0 & 2.4 & 1.8 \\
\hline
\end{tabular}

Note that the error estimates shown are used in the calculation of $x^{2}$.
TABLE 3

Oligocene inclination data

\begin{tabular}{llrll}
\hline Site & $\begin{array}{l}\text { Age } \\
(\mathrm{Ma})\end{array}$ & $\begin{array}{l}\text { Incl. } \\
\left({ }^{\circ}\right)\end{array}$ & $\begin{array}{l}\text { Std error } \\
\text { in incl. } \\
\left({ }^{\circ}\right)\end{array}$ & $\begin{array}{l}\text { Std error in } \\
\text { paleo-colat. } \\
\left({ }^{\circ}\right)\end{array}$ \\
\hline DSDP Site 523 & $30-40$ & -57.3 & 2.0 & 2.1 \\
ODP Site 706 & $33-35$ & -36.3 & 2.0 & 1.4 \\
Gubbio/Contessa & $25-38$ & 45.0 & 1.2 & 1.0
\end{tabular}

Note that the error estimates shown are used in the calculation of $\chi^{2}$.

all these paleomagnetic data are considered as inclination-only results.

From a study of the Contessa sections at Gubbio, we use the total (normal and reverse polarity) mean inclination $\left(45^{\circ}\right.$ ) found by Lowrie et al. [8] for Oligocene sediments which are well dated from biostratigraphy and magnetostratigraphy. For the Paleocene, we use the thermal demagnetization results of Roggenthen and Napoleone [9] for Gubbio $\left(42^{\circ}\right)$ rather than the Paleocene directions of Lowrie et al. [8] because the former are slightly better constrained ( $\alpha_{95}=5.9^{\circ}$ compared with $\alpha_{95}$ $\left.=8.8^{\circ}\right)$. In any case, the mean inclinations found in the two studies differ by only $3^{\circ}$. We calculate 1 -sigma errors on inclination from the published $\alpha_{95}$ value after applying the correction of Demarest [10], using only the inclination component of the full-vector average.

From the Mascarene Plateau, we use for the Oligocene interval results from ODP Site 706 [11] which are derived from a $40 \mathrm{~m}$ section of nannofossil ooze. In that study we calculated a mean inclination of $-36.3^{\circ}$ using a maximum likelihood method [12]. (Note that in computing the inclination, we took care to use McFadden and Reid's equation 40 with the unhatted value of $\theta$ and not the hatted value as was incorrectly used in their numerical example [P. McFadden, pers. commun., 1986], and so the maximum likelihood estimates of inclination are always steeper than the simple arithmetic average, as they ought to be.) Biostratigraphic evidence, in conjunction with the uniformly reverse polarity of Site 706 sediments, indicates an age between anomaly 12 and 13 time (32.90-35.29 Ma [13]); i.e., early Oligocene. We derive Paleocene data for the Mascarene Plateau from basement lavas at ODP Site 707 [14] rather than from sediments. The age of these lavas is constrained by the overlying Paleocene sediments 
as well as radiometric estimates which give $63.7 \pm$ $1.1 \mathrm{Ma}$ [15]. The reliability of these paleomagnetic data are somewhat suspect because it is not clear whether secular variation has been completely averaged; however, the average inclination $\left(-43.2^{\circ}\right)$ agrees reasonably well with more extensive paleomagnetic data from the Deccan Traps on the conjugate side of the Carlsberg Ridge $[16,17]$. We again calculate errors on inclination from the $\alpha_{95}$ value using Demarest's [10] correction factor. From the region of the Walvis Ridge, we use the inclination data from DSDP Leg 73, which were averaged in $5 \mathrm{~m}$.y. windows by Tauxe et al. [18] using the method of Kono [19]. For the Oligocene interval, we have used their $30-35$ and 35-40 Ma values from Site 523. These two values show substantial variation in inclination over this age range $\left(-53.3^{\circ}\right.$ for $30-35$ Ma compared with $-61.2^{\circ}$ for $35-40 \mathrm{Ma}$ ) and so we take the average of these two values $\left(-57.3^{\circ}\right)$ to be representative of the Oligocene. We further presume that the two inclination values given for $30-35$ and $35-40 \mathrm{Ma}$ represent the $95 \%$ error limit on our composite average (of $\pm 4^{\circ}$ ) and use this to estimate a standard error in inclination $\left( \pm 2^{\circ}\right)$. For the Paleocene interval, we use the $60-65 \mathrm{Ma}$ inclination average $\left(-64.2^{\circ}\right)$ from the sediments drilled at Site 524 [18], with the associated confidence limits.

\subsection{Paleocene result}

We compared the three Paleocene inclination data from the African plate to a wide range of non-dipole field models, varying both the modelled quadrupole and octupole contributions from -20 to $+20 \%$ of the geocentric axial dipole term (Fig. 2). The range of acceptable field models corresponds to those which give $\chi^{2}$ less than 3.8 for the $95 \%$ confidence region. Outside of this acceptance region, one can reject the null hypothesis that the field model fits the data. The critical value defining the acceptance region is determined from tabulated values of the $\chi^{2}$ distribution with 1 degree of freedom. (Because the latitude and longitude of the pole are also determined in the computation of $\chi^{2}$ for a given field model, the number of degrees of freedom is always two less than the number of observations.) The Paleocene results show that the acceptability of a particular field model depends primarily on the value of the octupole term (G3). Indeed, acceptable values of

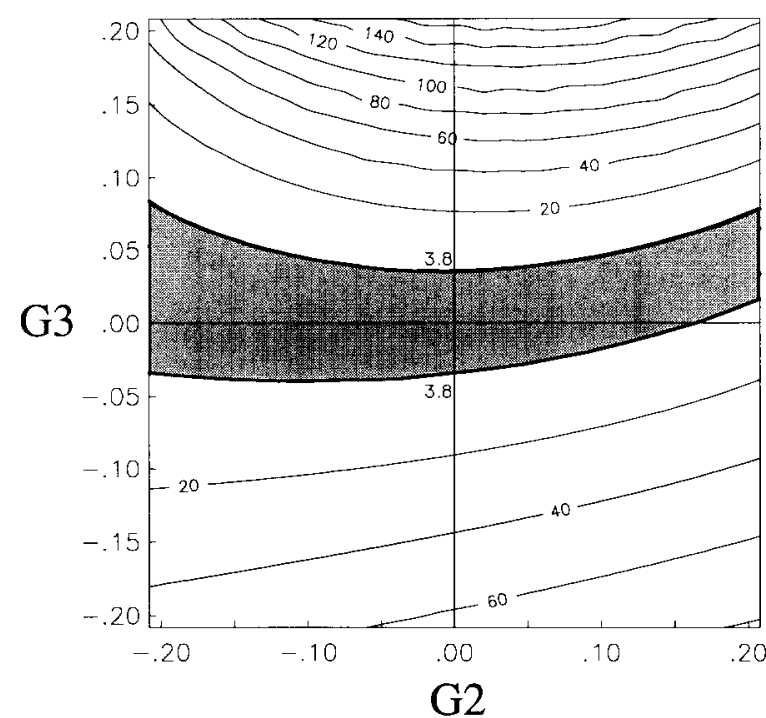

Fig. 2. Range of acceptable non-dipole field models for the Paleocene compatible with African plate data. Contours of reduced $\chi^{2}\left(x^{2} /\right.$ degrees of freedom) shown. Models which fall outside of the shaded area (defined by reduced $\chi^{2}=3.8$ ) can be rejected with $95 \%$ confidence.

the quadrupole $(G 2)$ cover a considerable range, from at least $-10 \%<G 2<+10 \%$. Within this range of quadrupole values, we find that the octupole must be between -4 and $+5 \%$ for the

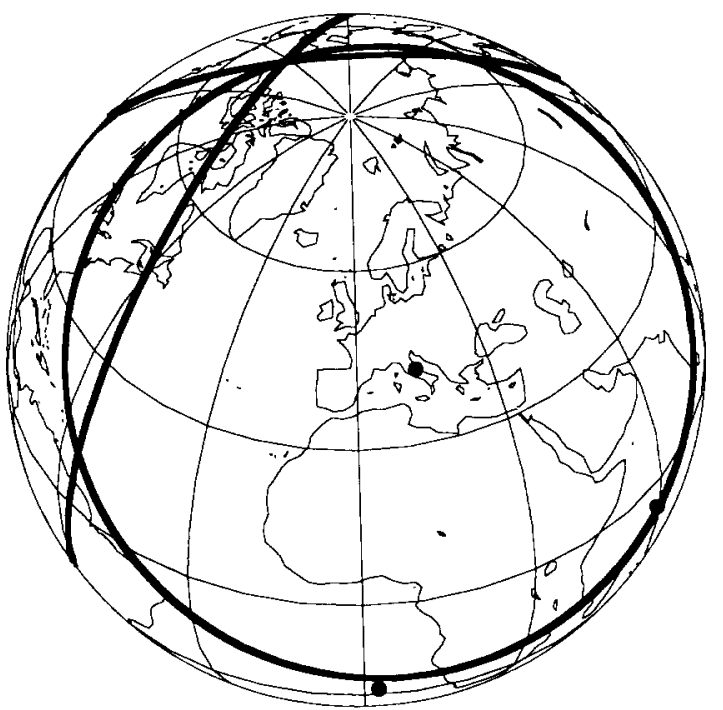

Fig. 3. Locus of allowable pole positions for the three Paleocene inclination-only sites analyzed (Table 2). Bold lines show small circles centered on each site and having a radius equal to the calculated paleo-colatitude. The three small circles intersect at one point using a GAD $(0 \% G 2,0 \% G 3)$ field model. 
TABLE 4

African pole positions derived from inclination-only results

\begin{tabular}{lllllll}
\hline Age & $\begin{array}{l}\text { Field } \\
\text { model }\end{array}$ & $\begin{array}{l}\text { Lat. }\left({ }^{\circ}\right) \\
(\mathrm{N})\end{array}$ & $\begin{array}{l}\text { Long. }\left({ }^{\circ}\right) \\
(\mathrm{E})\end{array}$ & $\begin{array}{l}\text { Semi-major } \\
\text { axis }\left({ }^{\circ}\right)\end{array}$ & $\begin{array}{l}\text { Semi-minor } \\
\text { axis }\left({ }^{\circ}\right)\end{array}$ & $\begin{array}{l}\text { Orientation }\left({ }^{\circ}\right) \\
(\mathrm{c} . w . \text { from N) }\end{array}$ \\
\hline Paleocene & GAD & 70.1 & -147.0 & 4.4 & 2.4 & 105 \\
Oligocene & GAD & 74.6 & -175.8 & 4.3 & 2.1 & 73 \\
Oligocene & NDF ${ }^{*}$ & 75.9 & -167.0 & 4.4 & 2.0 & 81 \\
\hline
\end{tabular}

Orientation of $95 \%$ error ellipse is specified as direction of semi-major axis.

* $0 \% \quad G 2,5 \% \quad G 3$.

model to be acceptable. Models having the octupole outside this range can be rejected at the 95\% confidence level. The best-fitting octupole value depends somewhat on the quadrupole, but is about 0 to $+1 \%$, assuming a reasonably small quadrupole field. Thus the Paleocene inclination data from Africa will give a consistent pole position using a standard GAD field model (Fig. 3). The location of this pole $\left(70.1^{\circ} \mathrm{N}, 147.0^{\circ} \mathrm{W}\right)$ is determined also by the fitting algorithm [6] (Table 4).

\subsection{Oligocene result}

The Oligocene results (Fig. 4) are similar in general form to those for the Paleocene. Again, the $\chi^{2}$ value depends primarily on the octupole and is not particularly sensitive to the quadrupole, at least over the range $-10 \%<G 2<+10 \%$.

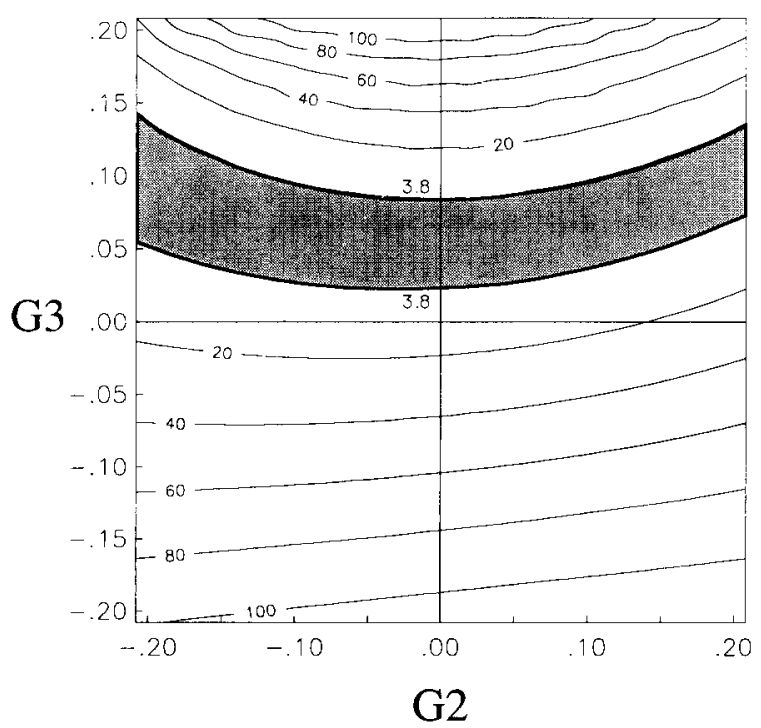

Fig. 4. Range of acceptable non-dipole field models for the Oligocene compatible with African plate data. Conventions as in Fig. 2.
Within this range of quadrupole values, the octupole can be no less than $3 \%$ or more than $10 \%$ for the model to be acceptable at the $95 \%$ confidence level. The best-fitting octupole (assuming a reasonably small quadrupole field) is about +5 to $+6 \%$. Thus Oligocene inclination data from Africa do not give a consistent pole position unless an octupole field correction is applied (Fig. 5). The location of the best-fitting pole, however, is not strongly dependent on the choice of field model (Table 4).

\section{Axial quadrupole}

\subsection{General considerations}

Although the paleomagnetic data from Africa are sufficient to limit the range of acceptable octupole values, they are clearly not adequate to determine the quadrupole component. To do this requires data from a wider distribution of longitudes than are available in this single-plate test. Below we attempt to constrain the allowable range of quadrupole values by including data from North America (after these data are restored to African coordinates). For this reconstruction we use the rotation parameters of Klitgord and Schouten [20], interpolated to ages of 62.5 and $35 \mathrm{Ma}$ for the nominal Paleocene and Oligocene intervals, respectively $\left(81.5^{\circ} \mathrm{N}, \quad-0.6^{\circ} \mathrm{E}, \quad \Delta=19.3^{\circ}\right.$ and $76.5^{\circ} \mathrm{N}, 7.5^{\circ} \mathrm{E}, \Delta=9.7^{\circ}$ ).

\subsection{North American paleomagnetic data}

From North America for the Oligocene, we use the $30-40 \mathrm{Ma}$ declination and inclination values ( $D=351.0^{\circ} ; I=47.3^{\circ} ; \alpha_{95}=4.4^{\circ}$ ) from a recent study of the Datil-Mogollon volcanic field in the southwestern United States [21]. We correct the declination at this site by $1.3^{\circ}$ to account for local clockwise rotation of the Colorado Plateau associ- 

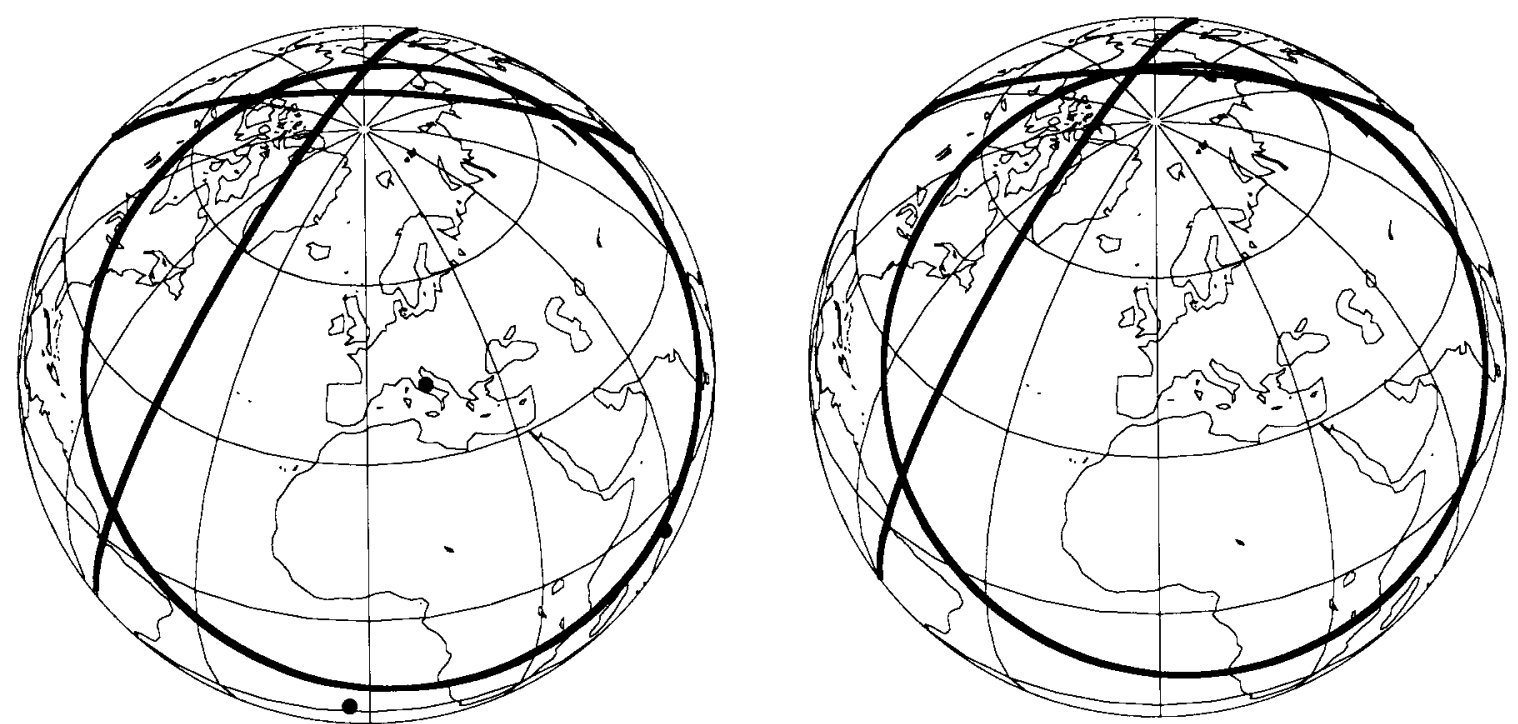

Fig. 5. Locus of allowable pole positions for the three Oligocene inclination-only sites analyzed (Table 3). Bold lines show small circles centered on each site and having a radius equal to the calculated paleo-colatitude. The three small circles do not intersect at one common location using a GAD (0\% G2, $0 \%$ G3) field model (left panel), but do intersect using a non-dipole (0\% G2, 5\% G3) field model (right panel).

ated with late Tertiary Rio Grande rifting [22]. The 1-sigma errors, using the method of Demarest $[10]$, are $\pm 2.6^{\circ}$ for the declination and $\pm 1.8^{\circ}$ for the inclination.

For the Paleocene, we use results from the

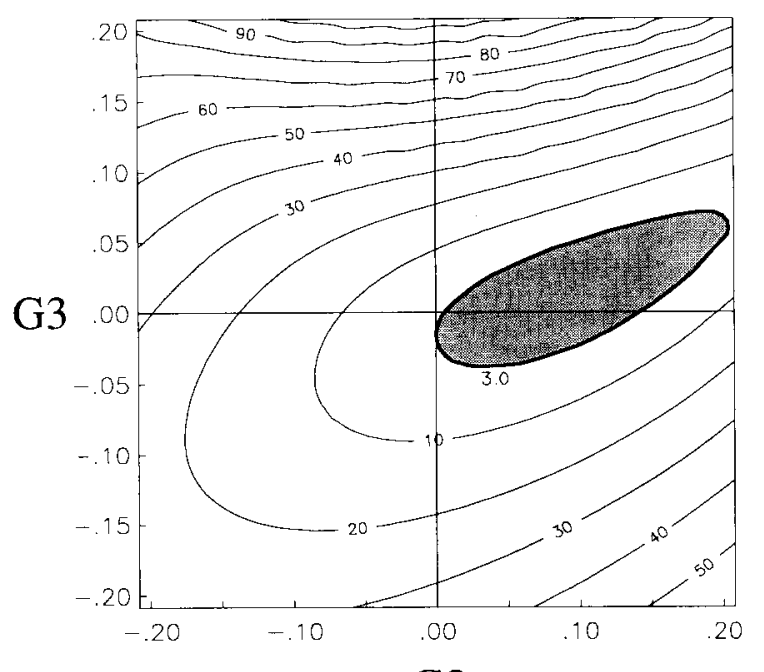

$\mathrm{G} 2$

Fig. 6. Range of acceptable non-dipole field models for the Paleocene compatible with African plate data and one North American declination result. The shaded $95 \%$ confidence region is defined by reduced $x^{2}=3.0$.
Nacimiento Formation [23] which is also located in the southwestern United States. Because the inclination results from these sediments have been thought to be artificially shallowed [24], we use only the declination $\left(D=343.9^{\circ}\right)$. A more critical

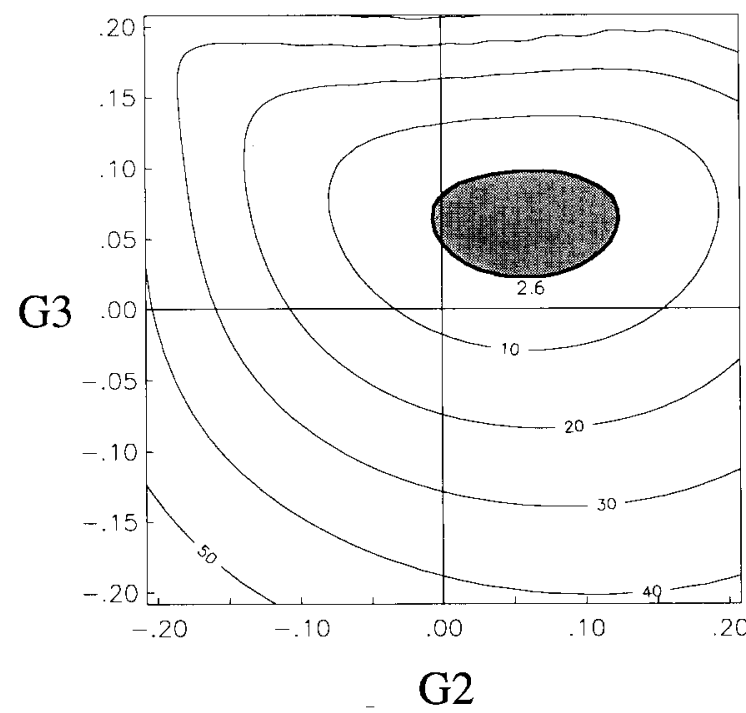

Fig. 7. Range of acceptable non-dipole field models for the Oligocene compatible with African plate data and one North American pole. The shaded 95\% confidence region is defined by reduced $\chi^{2}=2.6$. 
concern with this Paleocene result is to determine the amount of clockwise rotation experienced at this locality since the Paleocene. Although typical estimates for the total rotation of the Colorado Plateau are about $2-4^{\circ}[25,26]$, much of this rotation likely took place during the Cretaceous. For the purposes of this analysis, we use the same $1.3^{\circ}$ correction to declination that we adopted for the Oligocene (giving a corrected declination of 342.6 $\pm 3.8^{\circ}$ ), recognizing that the actual Paleocene value could be somewhat larger.

\subsection{Paleocene result}

The results after including the North American datum (Fig. 6) do not change the previous estimates of the octupole substantially. The acceptable range of the quadrupole component is, as anticipated, better constrained; however, a rather large range of values (from 0 to $+20 \%$ ) remain acceptable. The best-fitting value for the quadrupole is approximately $+10 \%$.

\subsection{Oligocene result}

For the Oligocene interval (Fig. 7), the allowable octupole range is also largely unchanged when the North American data are included. The range of acceptable quadrupole values is reduced to between -1 and $+12 \%$ ( $95 \%$ confidence). The best-fitting value for the quadrupole is about +5 to $+6 \%$.

\section{Discussion}

\subsection{Errors}

Although it is clear that the paleomagnetic data used here can be brought into agreement with a model of the time-averaged field that includes axial quadrupole and octupole terms, it is important to consider whether departures from GAD directions might be attributed to causes other than non-dipole fields. The most likely source of systematic error is spurious inclination shallowing. We may presume that the African results, which are largely from pelagic sediments, do not have a large original inclination error; however, the shallowing effects of later compaction of such sediments may be substantial [27]. Consequently we cannot conclude with any assurance that the octupole component suggested here reflects a true geomagnetic effect and so prefer instead to con- sider these results as an estimate of the maximum allowable positive value of $G 3$ (i.e., undetected inclination shallowing would correspond to larger apparent positive values of $G 3$ ).

A second possible source of error is our assumption that Gubbio constitutes part of the African plate. Our reasoning is based on the arguments of Channell et al. [7] who compared the relative motion of Africa and Europe with the timing of deformation in the periadriatic region and concluded that Adria had moved with Africa since the Mesozoic. However, given the tectonic complexity of the region, some caution is demanded. A southerly ancient position for Adria (with respect to Africa) would tend to increase the discrepancy in the dipole model and so, like compaction, would tend to exaggerate the size of the octupole fit. Conversely, a more northerly position would tend to decrease the octupole estimates. We note that the Paleocene results from Gubbio fit quite reasonably with the other sites from the African plate using zero octupole field. Although this may be the result of two counterbalancing effects (southward tectonic motion compensating for a positive octupole field), it appears more

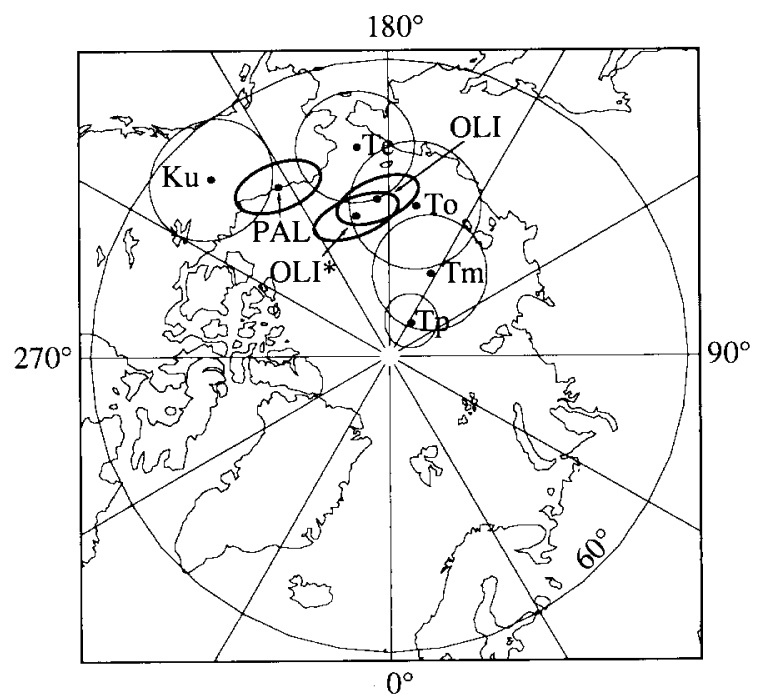

Fig. 8. Comparison of best-fitting pole positions (Table 4) to African APWP [18]. The poles calculated in this study are shown with bold $95 \%$ confidence ellipses $(P A L=$ Paleocene result using GAD model; $O L I=$ Oligocene result using GAD model; $O L I^{*}=$ Oligocene result using $5 \%$ octupole correction). Circular confidence limits of $95 \%$ are shown for the African APWP of $[18]$ ( $T p=$ Pliocene; $T m=$ Miocene; $T o=$ Oligocene; $T e=$ Eocene; $K u=$ Late Cretaceous) 
likely that Adria has, in fact, been part of the African plate since the Paleocene. Thus the association of the Gubbio sections with Africa appears justified for both Paleocene and Oligocene intervals.

The reliablility of the inclination data from the three regions studied is further suggested by our estimates of pole position which agree well with a prior estimate of the Tertiary apparent polar wander path for Africa [18] (Fig. 8). Indeed, it appears that this analysis of inclination-only results may provide better constrained Oligocene and Paleocene poles for Africa (Table 4) than are now available from fully oriented paleomagnetic data.

Note that we have not explicitly compensated for the effects of rifting in east Africa. Estimates show the total amount of opening of the rift to be minimal, in the range of several tens of kilometers [28], and so this motion may reasonably be neglected in our analysis.

As mentioned, the difficulty in determining the timing and amount of rotation of the Colorado Plateau does add considerable uncertainty to the declination data from North America. A larger (uncorrected) clockwise rotation would give rise to greater positive estimates of $G 2$. For example, increasing the declination result from North America by $1^{\circ}$ would increase the estimate of $G 2$ by $2 \%$. Thus caution is clearly warranted in testing quadrupole field models with these data. (A better version of this test of quadrupole field models might be formulated when adequate paleomagnetic data are available from more stable parts North America.) Nevertheless, a general assessment of the size and polarity of the quadrupole field can be reasonably deduced for the Tertiary.

\subsection{Comparison with prior models}

We can compare our results with non-dipole field studies by Coupland and Van der Voo [2] and of Livermore et al. [5] which have attempted to describe the paleomagnetic field for the Tertiary (and even earlier times). In all but one case (the declination of the Nacimiento result), the data we have used are independent; i.e, they were not used in these previous studies. Note that Livermore et al. [5] anticipated difficulty fitting an octupole field and so restricted their study to the lower-degree quadrupole term. In contrast, our method allows the octupole, which will have a detectable effect on data from a single suitablylocated plate, to be estimated most readily. Note that in presenting their results, Coupland and Van der Voo [2] normalized their non-dipole field estimates by the absolute magnitude of the dipole field and thus we must invert the sign of their estimates to make a comparison. For the interval between 30 and $40 \mathrm{Ma}$, Coupland and Van der Voo [2] determined a quadrupole of about $-3 \%$ and an octupole of about $+12 \%$. Such a field configuration is not compatible with our tests (Fig. 9). Indeed, our results indicate that the octupole component may be about +5 to $+6 \%$ and can be no greater than $+10 \%$ (at a $95 \%$ confidence level) unless the quadrupole takes on somewhat extreme values: less than $-10 \%$ or greater than $+10 \%$, but this does not appear likely. For 60-65 Ma, Coupland and Van der Voo [2] suggested a more moderate octupole value of about $+4 \%$ which is consistent with the acceptability range found here (Fig. 9).

The reason for the discrepancy in the Oligocene octupole value is not clear. It may be that some of
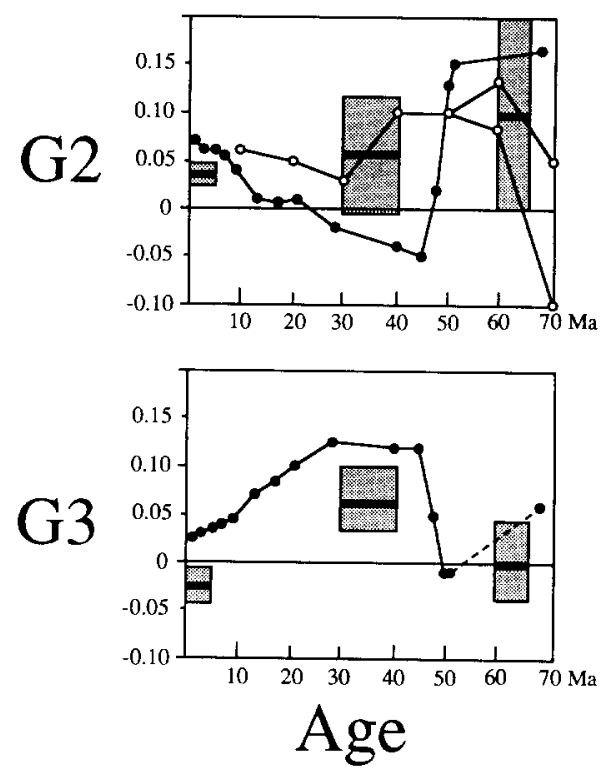

Fig. 9. Comparison of allowable ranges for quadrupole $(G 2)$ and octupole $(G 3)$ non-dipole components found in this analysis with previous studies $[2,4,5]$. Dots show quadrupole + octupole model of [2]; circles show alternative quadrupole models of [5]. 0-5 Ma results are from [4]; 30-40 and 60-65 Ma results are from this study. Shaded areas indicate $95 \%$ errors on non-dipole estimates. 
the paleomagnetic data used in the study of Coupland and Van der Voo [2] is severely affected by a spurious inclination error, which would shallow inclination and appear as a positive octupole component in a non-dipole analysis [4]. Or it may simply be that Coupland and Van der Voo [2] used an incorrect term in calculating the octupole effect [4]. Indeed, if this latter explanation is correct, then their octupole estimates should be reduced by about half, which would give quite good agreement with the African plate test formulated here.

Our evaluation of the quadrupole $(\sim 6 \%)$ for the Oligocene is not well constrained; nevertheless, the large range we find (-1 to 13\%) is still not compatible with the $-3 \%$ estimate Coupland and Van der Voo [2] determined with their quadrupole + octupole model. Our results are in better agreement with the quadrupole-only model of Livermore et al. [5] who found a quadrupole between 3 and $10 \%$ for this interval. For the Paleocene, the models of Coupland and Van der Voo [2] suggest a substantial quadrupole of about $16 \%$ which is within the range we found to be acceptable $(0-20 \%)$. The analysis of Livermore et al. [5] for this interval depends on the data set analyzed. When they include Deccan paleomagnetic poles in their analysis, their quadrupole estimate is about $9 \%$ over the $60-70 \mathrm{Ma}$ interval. This would match our results. With Deccan data excluded, their quadrupole result undergoes an abrupt change from about -10 to $+10 \%$ over the 60-70 $\mathrm{Ma}$ interval and thus matches our results only at the younger end of this apparent trend.

\subsection{Implications}

The previous spherical harmonic studies suggested that there have been intervals during the Tertiary with rather large non-dipole fields that have quadrupole or octupole components of $10 \%$ or more. One study [2] further indicated that the quadrupole component of the field may have changed in sign over the Tertiary. We find that the octupole probably was not so large as was suggested. The best-fitting values found in this study would indicate that the quadrupole has decreased in magnitude from about $10 \%$ during the earliest Tertiary to about $3-4 \%$ during the past few million years; however, the errors on the Tertiary estimates of the quadrupole field are considerable.
Thus, our results cannot rule out a large quadrupole field (of perhaps 10\% or more) during the earliest Tertiary, but data analyzed here do not demand such extreme values. The data do not, in any case, indicate any change of sign for the quadrupole. Because some positive quadrupole is required for all intervals tested, we suggest that the +3 to $+4 \%$ quadrupole field found for the past few million years [4] remains a reasonable field model to apply throughout the entire Tertiary. This conclusion would indicate that the usual dipole assumption of paleomagnetism may be improved upon in a systematic way so as reduce errors in determining the true position of the geographic pole. Below we explore what may be two related examples of this: the drift of Africa during the past $30 \mathrm{Ma}$ and the paleolatitude of the Deccan Traps.

Drift of Africa. The motion of Africa has been determined independently of paleomagnetic data using the traces of several oceanic hotspots [29]. This method assumes that these hotspots are relatively stable, an assumption that can be tested
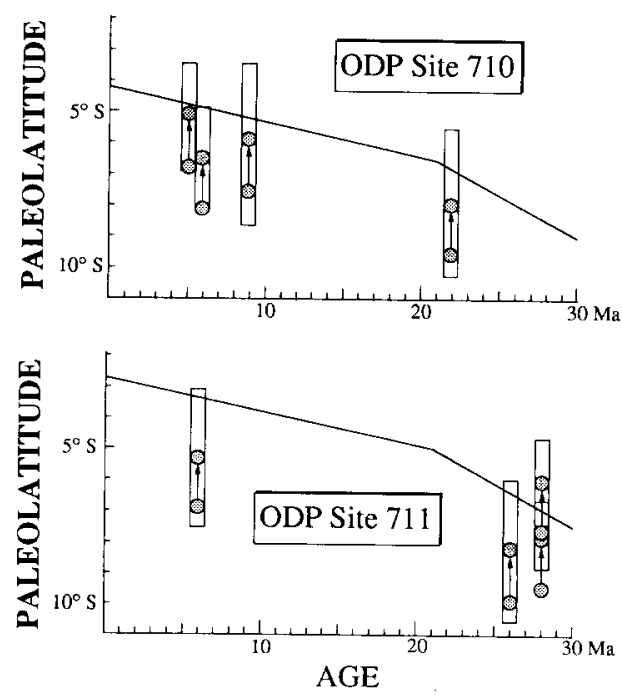

Fig. 10. Paleolatitude evolution of Ocean Drilling program Sites $710\left(4.32^{\circ} \mathrm{S}, 60.98^{\circ} \mathrm{E}\right)$ and $711\left(2.75^{\circ} \mathrm{S}, 61.17^{\circ} \mathrm{E}\right)$ east of the Seychelles Bank near the eastern margin of the African plate. Solid lines show prediction based on a fixed African hotspot model [29]. Shaded circles show the paleolatitudes estimated from paleomagnetic inclination data before (arrow tail) and after (arrow point) introducing a non-dipole correction (3.8\% quadrupole component) [11]. Open bars indicate $95 \%$ errors on non-dipole corrected estimates of paleolatitude. 
using paleomagnetism. Such a test, however, will depend fundamentally on the model used for the time-averaged geomagnetic field.

In examining the paleomagnetic results from deep-sea sediments cored during ODP Leg 115 [11], we invoked a field model which included a quadrupole component of $3-4 \%$, equal to that of the last few million years [4]. This non-dipole correction reconciled the inclinations measured in cores from two sites on the Madingley Rise (easternmost African plate) with a hotspot-based plate motion model for Africa [29] (Fig. 10). Indeed it would appear that a non-dipole field correction is the only sensible way to reconcile the paleomagnetic data from these two sites with African hotspot tracks. Spurious inclination shallowing cannot explain the discrepancy because the observed inclinations are steeper than hotspot-based predictions. Nor does drift of the hotspots seem likely: the discrepancy between the hotspot and paleomagnetic predictions of paleolatitude is relatively constant from 5 to $28 \mathrm{Ma}$; thus these data do not suggest the steady incremental change that might be expected from a constant drift of the hotspots.

Paleolatitude of the Deccan Traps. The Deccan Traps are thought to represent the initiation of a hotspot which is presently located beneath Réunion Island in the southwest Indian Ocean [30]. It has been noted [14] that the latitude of Reunion Island $\left(21^{\circ} \mathrm{S}\right)$ is somewhat north of the paleolatitude determined for the source of the Deccan Traps using paleomagnetic data (about $26^{\circ} \mathrm{S}$ assuming a GAD field model). Because the presentday latitude of the hotspot is outside the range of statistical errors for the estimate of Deccan paleolatitude $\left(22.5-30^{\circ} \mathrm{S}\right)$, it was suggested that there may have been about $5^{\circ}$ of latitudinal drift of the Réunion hotspot over the Cenozoic [14]. This analysis, however, is better carried out taking account of the non-dipole field. Although the octupole field during the earliest Tertiary is minimal, some positive quadrupole component appears to be required during this period. As we have argued, a conservative value to use for this may be +3 to $+4 \%$, as found for the Plio-Pleistocene. Because the Plio-Pleistocene quadrupole field is somewhat larger during reverse polarity intervals than during normal polarity [4], we presume that a value near
$+4 \%$ is appropriate to apply to the largely reversed polarity Deccan Trap rocks.

Recalculating the paleolatitude of the Deccan source region [14] using a $4 \%$ quadrupole model, we find a paleolatitude range that is shifted $2^{\circ}$ to the north relative to that found with a GAD model. Assuming a full $10 \%$ quadrupole field would correspond to a $5^{\circ}$ shift to the north. Thus even a conservative value for the quadrupole suggests that the source of the Deccan Traps was located between about 20.5 and $28^{\circ} \mathrm{S}$, a range compatible with the present-day $21^{\circ} \mathrm{S}$ latitude of the Réunion hotspot. Moreover, taking the 10\% quadrupole value would virtually center the revised estimate of the paleolatitude range $\left(17.5-25^{\circ}\right.$ S) on the present latitude of Réunion.

\section{Conclusions}

Although it may be difficult to extend traditional spherical harmonic analysis of the paleomagnetic field to remote epochs, it remains possible to estimate at least the octupole coefficient by examining the variation of the field over an individual plate. In this analysis we are able to estimate the axial octupole using data from Africa alone because this plate covered a considerable range of latitude in both northern and southern hemispheres. We find the octupole contribution to the field to be at most several percent of the geocentric axial dipole, similar in magnitude (but not sign) to Plio-Pleistocene values.

We are further able to gauge the size of the axial quadrupole by linking Africa to North America. Although the estimation of this component is poorly constrained both because of statistical uncertainty in the data and because of the possible systematic effects of local tectonic rotation, our results generally support the notion that a positive quadrupole is appropriate for the entire Tertiary. We argue that it is reasonable to apply this estimate of the quadrupole determined for the Plio-Pleistocene to all of the Cenozoic. To i1lustrate some important practical consequences to this refinement of the paleomagnetic method, we have shown how the recognition of a quadrupole field allows paleomagnetic data from two ODP sites on the African plate to match the predictions derived from a hotspot-based plate motion model. We showed similarly that paleomagnetic data from 
the Deccan Traps are consistent with the Réunion hotspot having remained fixed since its initiation. The consistency so afforded by a non-dipole refinement to the geocentric axial dipole assumption suggests that a non-dipole correction may be profitably applied in detailed tectonic studies.

\section{Acknowledgements}

We gratefully acknowledge the help of Richard Gordon in sending us a copy of his computer program for computing poles from oceanic plates. We further thank Steve Cande and Rich Jarrard for their constructive comments on the manuscript. This work was supported by US National Science Foundation (NSF grant EAR 88-17773) and NATO/NSF postdoctoral fellowship support (NSF grant RCD-8953801) for DAS. Centre des Faibles Radioactivités contribution 1112. LamontDoherty Geological Observatory contribution 4614.

\section{References}

1 R.T. Merrill and M.W. McElhinny, Anomalies in the timeaveraged paleomagnetic field and their implications for the lower mantle, Rev. Geophys. 15, 309-323, 1977.

2 D.H. Coupland and R. van der Voo, Long-term components in the geomagnetic field during the last $130 \mathrm{~m} . \mathrm{y} ., \mathrm{J}$. Geophys. Res. 85, 3529-3548, 1980.

3 R.A. Livermore, F.J. Vine and A.G. Smith, Plate motions and the geomagnetic field-I. Quaternary and late Tertiary, Geophys. J. R. Astron. Soc. 73, 153-171, 1983.

4 D.A. Schneider and D.V. Kent, The time-averaged paleomagnetic field, Rev. Geophys., in press, 1990.

5 R.A. Livermore, F.J. Vine and A.G. Smith, Plate motions and the geomagnetic field-II. Jurassic to Tertiary, Geophys. J. R. Astron. Soc. 79, 939-961, 1984.

6 R.G. Gordon and A. Cox, Calculating paleomagnetic poles for oceanic plates, Geophys. J. R. Astron. Soc. 63, 619-640, 1980.

7 J.E.T. Channell, B. D'Argenio and F. Horvath, Adria, the African promontory, in Mesozoic Mediterranean paleogeography, Earth Sci. Rev. 15, 213-292, 1979.

8 W. Lowrie, W. Alvarez, G. Napoleone, K. Perch-Nielsen, I. Premoli Silva and M. Toumarkine, Paleogene magnetic stratigraphy in Umbrian pelagic carbonate rocks: The Contessa sections, Gubbio, Geol. Soc. Am. Bull. 93, 414-432, 1982.

9 W.M. Roggenthen and G. Napoleone, Upper-CretaceousPaleocene magnetic stratigraphy at Gubbio, Italy: IV. Upper Maastrichtian-Paleocene magnetic stratigraphy, Geol. Soc. Am. Bull. 88, 367-389, 1977.

10 H.H. Demarest, Error analysis for the determination of tectonic rotation from paleomagnetic data, J. Geophys. Res. 88, 4321-4328, 1983.

11 D.A. Schneider and D.V. Kent, Paleomagnetism of Ocean Drilling Program Leg 115 sediments: implications to Neogene magnetostratigraphy and paleolatitude of the Réunion hotspot, Proc. Ocean Drill. Program, Init. Rep. 115B, in press, 1990.

12 P.L. McFadden and A.B. Reid, Analysis of paleomagnetic inclination data, Geophys. J. R. Astron. Soc. 69, 307-319, 1982.

13 W.A. Berggren, D.V. Kent and J.A. van Couvering, Neogene geochronology and chronostratigraphy, in: The Chronology of the Geological Record, N.J. Snelling, ed., Mem. No. 10 Geol. Soc., Blackwell, Oxford, 1985.

14 D. van Damme and V. Courtillot, Paleomagnetism of Leg 115 basement rocks and latitudinal evolution of the Réunion Hotspot, Proc. Ocean Drill. Program, Init. Rep. 115B, in press, 1990.

15 R.A. Duncan and R.B. Hargraves, ${ }^{40} \mathrm{Ar}-{ }^{39} \mathrm{Ar}$ Geochronology of basement rocks from the Mascarene Plateau, Chagos Bank and the Maldives Ridge, Proc. Ocean Drill. Program, Init. Rep. 115B, in press, 1990.

16 C.T. Klootwijk, A review of paleomagnetic data from the Indo-Pakistani fragment of Gondwanaland, in: Geodynamics of Pakistan, A. Farah and K.A. DeJong, eds., pp. 41-80, 1979.

17 V. Courtillot, J. Besse, D. Vandamme, R. Montigny, J.-J. Jaeger and H. Cappetta, Deccan flood basalts at the Cretaceous/Tertiary boundary?, Earth Planet. Sci. Lett. 80, 361374, 1986.

18 L. Tauxe, J. Besse and J.L. LaBrecque, Palaeolatitudes from DSDP Leg 73 sediment cores: implications for the apparent polar wander path for Africa during the late Mesozoic and Cenozoic, Geophys. J. R. Astron. Soc. 73, 315-324, 1983.

19 M. Kono, Statistics of paleomagnetic inclination data, J. Geophys. Res. 85, 3878-3882, 1980.

20 K.D. Klitgord and H. Schouten, Plate kinematics of the central Atlantic, in: The Geology of North America, v. M, The Western North Atlantic Region, Geol. Soc. Am., 1986.

21 J.F. Diehl, K.M. McClannahan and T.J. Bornhorst, Paleomagnetic results from the Mogollon-Datil volcanic field, Southwestern New Mexico, and a refined mid-Tertiary reference pole for North America, J. Geophys. Res. 93,4869-4879, 1988.

22 L. Cordell, Extention in the Rio Grande Rift, J. Geophys. Res. 87, 8561-8569, 1982.

23 R.F. Butler and L.H. Taylor, A middle Paleocene paleomagnetic pole from the Nacimiento Formation, San Juan Basin, New Mexico, Geology 6, 495-498, 1978.

24 R.G. Gordon, A Paleocene North American paleomagnetic pole incorporating declination-only data, Geophys. Res. Lett. 11, 477-480, 1984.

25 W. Hamilton, Plate-tectonic mechanism of Laramide deformation, Contrib. Geology, University of Wyoming, 19 , $87-92,1981$.

26 P. Bryan and R.G. Gordon, Rotation of the Colorado Plateau: An analysis of paleomagnetic data, Tectonics 5, 661-667, 1986.

27 M.A. Ceyala and B.M. Clement, Inclination shallowing in 
deep-sea sediments from the North Atlantic, Geophys. Res. Lett. 15, 52-55, 1988.

28 D. McKenzie, D. Davies and P. Molnar, Plate Tectonics of the Red Sea and East Africa, Nature 226, 243-248, 1970

29 R.A. Duncan, Hotspots in the Southern Oceans-an ab- solute frame of reference for motion of the Gondwana continents, Tectonophysics 74, 29-42, 1981.

30 M.A. Richards, R.A. Duncan and V.E. Courtillot, Flood basalts and hot-spot tracks: plume heads and tails, Science 246, 103-107, 1989. 